\title{
Analytical dependence of substance solubility measure on temperature
}

\author{
Zdzisław Pluta, Tadeusz Hryniewicz* \\ Koszalin University of Technology, Raclawicka 15-17, PL 75-620 Koszalin, Poland \\ *E-mail address: Tadeusz.Hryniewicz@tu.koszalin.pl
}

\begin{abstract}
The work covers an adequate analytical dependence of solubility measure of the chemical substances on the water/aqueous solution temperature. The solubility was defined and new, more readable solubility measure was introduced; the coefficient of solubility has been proposed instead. Then the source differential equation was introduced as the basis for the derivation of a final analytical form of dependence of the solubility coefficient on temperature. That characteristics has been developed by determining the dependence of the solubility coefficient variability intensity on temperature. An example of the use of presented theory has been delivered by referring it to the phenomenon of dissolution of $\mathrm{AgNO}_{3}$ silver nitrate in the aqueous environment. In the summary, quite a developed use of the source differential equation has been underlined with some more examples revealed.
\end{abstract}

Keywords: Solubility; Substance; Temperature; Potential field; Temperature-solubility space; Temperature constant; Solubility coefficient; Intensity of changes of the solubility coefficient

\section{INTRODUCTION}

On the ground of science, there is often noted an approach to elaborate the experimental results leading to formulate a description of empirical, statistic-experimental model. The main flaw of that model is lack of a physical sense.

There is a necessity to substitute that model by another one, more adequate. It has been called the reason model with a physical sense. Such a kind of model possesses constants determined by units with clearly assigned content interpretations. Literature [1] discusses such models though with a limited exemplification material.

The monograph [2] develops the subject by presentation of a new approach to the description of phenomena or processes coming out of the source differential equation. The work [2] is referred to the technological process of smoothing using elastic abrasive wheels but this kind of approach may be developed and referred to other cognitive issues.

That approach may be referred also to the chemistry. One of the examples of using the source differential equation is the work [3], covering energetic development of the kinetics description of the catalytic reactions occurring in the presence of proteolytic enzymes [4-7]. The analytical dependence of the substance solubility measure on temperature was elaborated based on this by referring the dependence to different exemplary chemical substances. 


\section{REMARKS ON SOLUBILITY}

The solubility phenomenon has been described in numerous references, e.g. [8-14]. However, the literature treats the solubility as a physical magnitude, i.e. measurable one, not separating its essence. It is known that the solubility, as the phenomenon, is a sensual magnitude, acquiring a determined measure which is the measurable magnitude, or just a physical magnitude.

One may admit that there are also mental and material magnitudes in the chain of all magnitudes; all they are ordered as follows: mental, sensual, physical, and material. The literature [15-17] discussed these cognitive issues, providing some examples of particular magnitudes. It is worth mentioning that the energy is one of many mental magnitudes, with the potential as its measure.

Coming to the notion of solubility, its definition is as follows: the substance solubility is the ability to dissolve in a determined solvent. (The water fulfills the role of the solvent in the considerations presented in this work). We do not measure the solubility; such a measurement is performed in reference to the solubility measure, being a physical magnitude. Such a measure is e.g. a maximum number of grams of a substance which, under determined conditions (determined by temperature and pressure), dissolves in one hundred grams of a solvent (here - water), forming a saturated solution. Thus the measure is the mass of the dissolved substance, i.e. $m_{s}$.

Discussed herewith the solubility phenomenon of chemical substances is described by two variable physical magnitudes, namely the solubility measure and temperature. On the ground of chemistry, it is considered the dependence of a substance mass dissolved in one hundred grams of water (solvent), so $m_{s}=f(t)$. Mass with its titre, in gram, is the measure of the solubility. The presented in literature the measure in grams per 100 grams of water indicates it is rather a quotient, a dimensionless coefficient, which is not true.

One may finally solve the problem by introducing a coefficient of solubility of the following form:

$$
c_{r}=\frac{m_{s}}{100 g H_{2} O}
$$

where: $c_{r}-$ the coefficient of solubility; $m_{s}$ - mass of a substance; with the denominator informing that the substance mass is referred to one hundred grams of water. Of course, the mass of that dissolved substance is expressed also in grams, thus the coefficient appears to be the dimensionless magnitude.

Furthermore, the dependences of type $c_{r}=f(t)$, i.e. the dependences of the substance solubility coefficient on temperature will be considered. Based on the data excerpted from [13] the plot of that dependences (Fig. 1) for silver nitrate $\mathrm{AgNO}_{3}$, sodium nitrate $\mathrm{NaNO}_{3}$, and potassium nitrate $\mathrm{KNO}_{3}$ have been performed. One may clearly notice, the coefficient of solubility rises with temperature, with the course being exponential and progressively rising in character. 


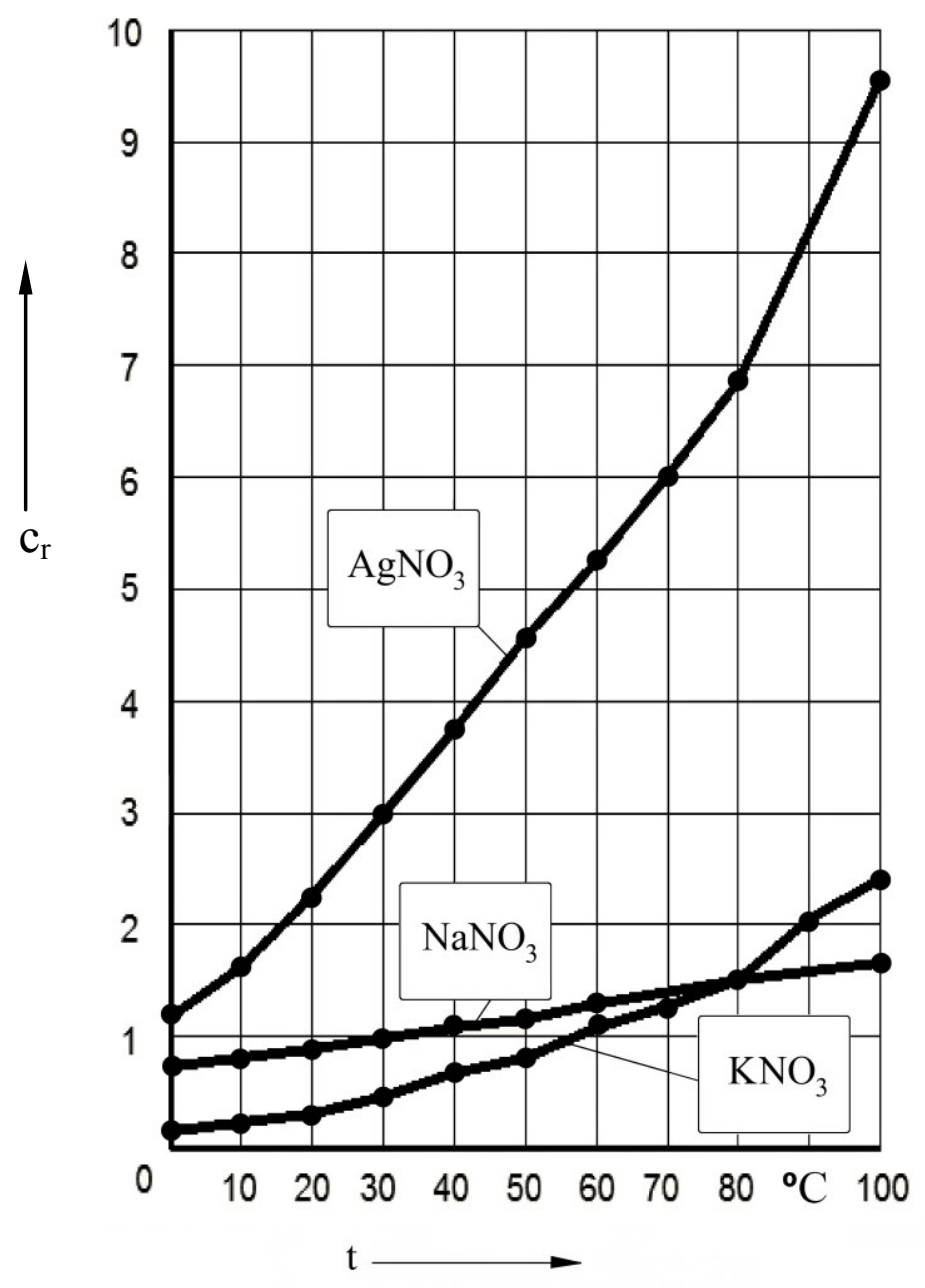

Fig. 1. Dependence of solubility coefficient $c_{r}$ on temperature $t$ for the nitrides of: silver $\left(\mathrm{AgNO}_{3}\right)$, sodium $\left(\mathrm{NaNO}_{3}\right)$, and potassium $\left(\mathrm{KNO}_{3}\right)$

Many other chemical substances have been considered concerning their solubility, presented in Fig. 2, of respectively extended scale of this magnitude to increase the transparency of this picture. The courses 2, 8, 9 come from the literature [8], and others result form the work [13].

One may notice, the curve referred to barium hydroxide $\mathrm{Ba}(\mathrm{OH})_{2}$ is really rising, but with the intensities of the coefficient growth $c_{r}$ being clearly divided into two temperature ranges; up to the temperature $t=60{ }^{\circ} \mathrm{C}$ the intensities of growth are moderate, whereas above that temperature these intensities rise quite vehemently.

It is worth noting a non-typical course of the solubility of the sodium sulfate with the solubility rising up to the temperature of $32{ }^{\circ} \mathrm{C}$, and then decreasing. The abnormal course of the solubility curve is caused by the transition of the aqueous sodium sulfate into an anhydrous salt: 


$$
\mathrm{Na}_{2} \mathrm{SO}_{4} \cdot 10 \mathrm{H}_{2} \mathrm{O} \leftrightarrow \mathrm{Na}_{2} \mathrm{SO}_{4}+10 \mathrm{H}_{2} \mathrm{O}
$$

at the temperature of $32.384{ }^{\circ} \mathrm{C}$.

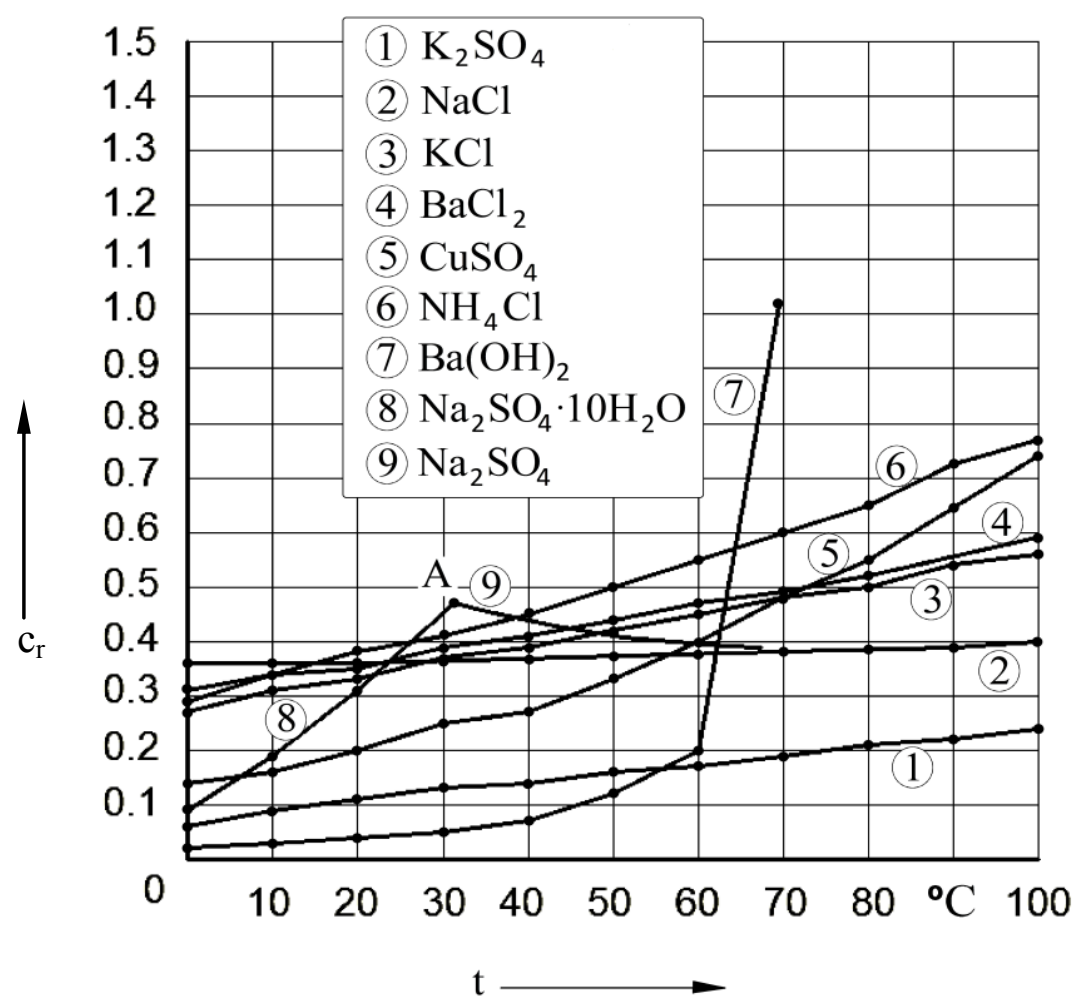

Fig. 2. Dependence of solubility coefficient $c_{r}$ on temperature $t$ for different chemical substances

At the sodium sulfite solubility plot (Fig. 2) the curve on left of the point A presents the equilibrium of saturated and aqueous sodium sulfate whereas the curve on the right of the point A presents the solubility of anhydrous sodium sulfate. The remaining curves $(1,2,3,4$, $5,6)$ possess exponential and progressively rising courses in the entire interval of the temperature changes. These curves have been done for the following substances: 1 potassium sulfate $\mathrm{K}_{2} \mathrm{SO}_{4} ; 2$ - sodium chloride $\mathrm{NaCl} ; 3$ - potassium chloride $\mathrm{KCl} ; 4$ - barium chloride $\mathrm{BaCl}_{2}$; copper sulfate $\mathrm{CuSO}_{4}$; and 6 - ammonium chloride $\mathrm{NH}_{4} \mathrm{Cl}$. All of these curves may be described analytically, however in this work the attention has been focused on the description of more frequently occurring curves, that is the exponential progressively rising ones. Now the adequate dependence, resulting from the source differential equation, will be derived. That function will be further approximated with the determined sets of experimental points.

\section{SOURCE DIFFERENTIAL EQUATION AND ITS REFERENCE TO THE SOLUBILITY PHENOMENON OF CHEMICAL SUBSTANCES}

At the very beginning of these considerations it is worth presenting the general form of the source differential equation; the form referred to all phenomena and processes having a quantum course, that is changing by a jump. The considerations are referred to a macro-scale. 
Of course, that kind of changes refers to the states, and not the transient between the states with continuous changes of the determined magnitude taking place between them.

The mentioned differential equation, excerpted from [2], has the following form:

$$
d Z= \pm \frac{\partial Z}{\partial N} d N
$$

where: $d Z$ - total differential of the dependent variable; $d N$ - total differential of the independent variable; $\frac{\partial Z}{\partial N}$ - partial derivative of the dependent variable, referred to the independent variable. The signs $( \pm)$ are the algebraic operators fulfilling a determined role. The sign $(+)$ has a formal meaning, confirming just the physical sense of a determined dependence. The sign $(-)$ ascribes such a sense to the determined record.

The considered here the phenomenon of solubility of chemical substances is described by two magnitudes, namely the determined solubility coefficient and temperature. Therefore the place of the dependent variable will be substituted by this coefficient with the temperature assuming the role of the independent variable.

After these explanations, the equation (3) assumes the following form:

$$
d c_{r}= \pm \frac{\partial c_{r}}{\partial t} d t
$$

and because the course of the considered magnitude is exponential and progressively rising, then

$$
d c_{r}=\frac{\partial c_{r}}{\partial t} d t
$$

The scheme of creation of the adequate description of the dependence $c_{r}=f(t)$ has been presented in Fig. 3 covering all elements of the reasoning process. The curve illustrating that dependence comes out of the initial point , 0 " of the coordinates $t=0, c_{r}=c_{r}^{0}$, and further having the exponential rising course. Its non-linear course is ended in the point „1", where the phenomenon of the substance dissolution is terminated. Now the dependence (5) should be integrated on both sides; one should remember here the total differential is the state function. Further on, the states, or the integration limits, should be determined. The mentioned limits, relating to the studied phenomenon, are the potential fields. These fields are situated on two directions; one of them is the direction of changes of the solubility coefficient $c_{r}$, whereas the second one is the direction of temperature $t$. On the first direction one may differentiate: solubility bottom stable potential field $(B S P F)_{c_{r}}$, solubility top stable potential field $(T S P F)_{c_{r}}$, solubility unstable potential field $(A P F)_{c_{r}}$. On the second direction, there are the following fields: temperature stable potential field $(S P F)_{t}$, temperature unstable potential field $(A P F)_{t}$. The fields $(T S P F)_{c_{r}},(A P F)_{c_{r}}$, and $(S P F)_{t}$ and $(A P F)_{t}$ limit the temperature-solubility space (dotted area), where the phenomenon of the substance solubility growth occurs. 


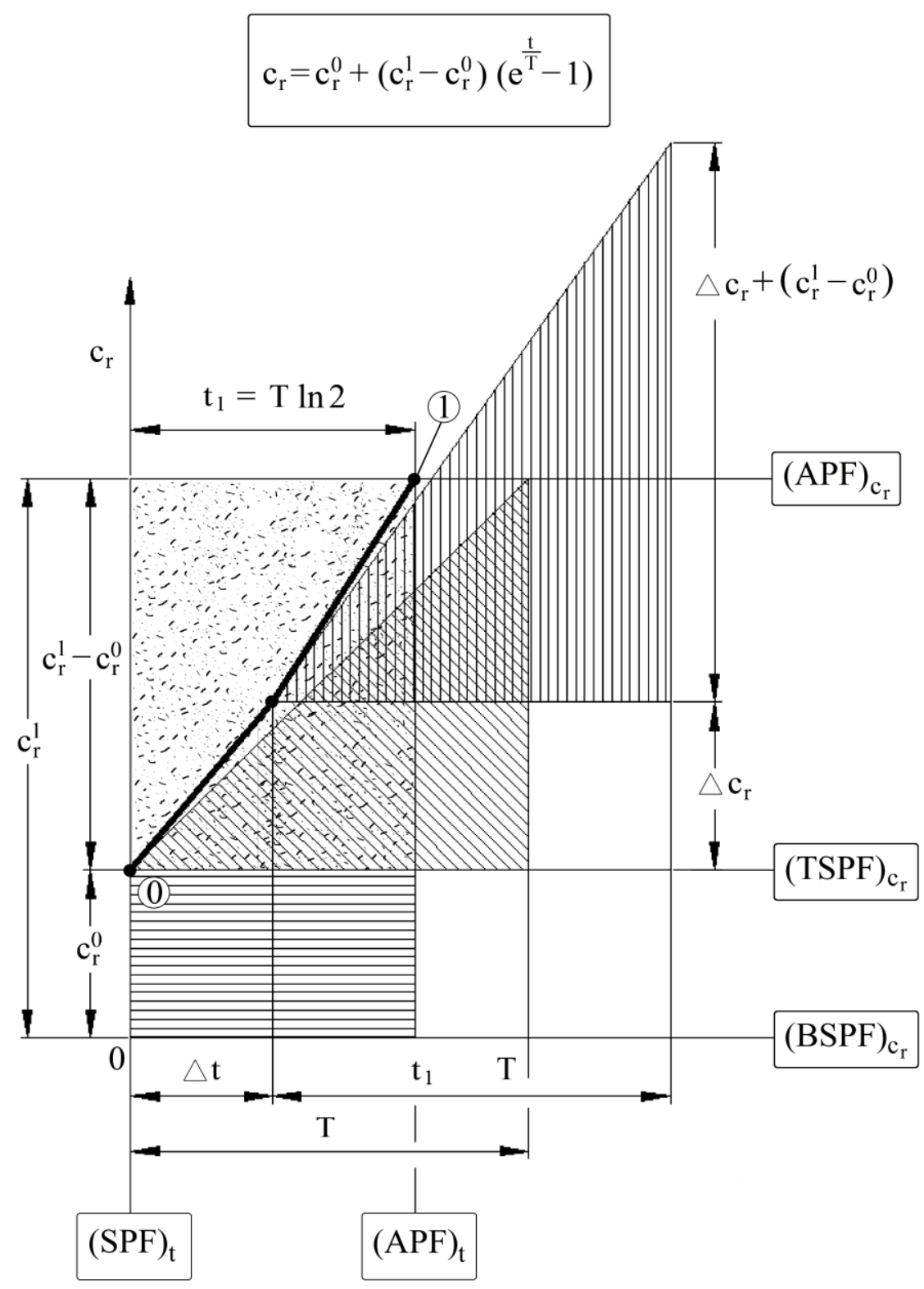

Fig. 3. Indicatrisse of the adequate course of the dependence of solubility coefficient on temperature

Now the dependence (5) should be integrated on both sides; one should remember here the total differential is the state function. Further on, the states, or the integration limits, should be determined. The mentioned limits, relating to the studied phenomenon, are the potential fields. These fields are situated on two directions; one of them is the direction of changes of the solubility coefficient $c_{r}$, whereas the second one is the direction of temperature $t$. On the first direction one may differentiate: solubility bottom stable potential field $(B S P F)_{c_{r}}$, solubility top stable potential field $(T S P F)_{c_{r}}$, solubility unstable potential field $(A P F)_{c_{r}}$. On the second direction, there are the following fields: temperature stable potential field $(S P F)_{t}$, temperature unstable potential field $(A P F)_{t}$. The fields $(T S P F)_{c_{r}}$, $(A P F)_{c_{r}}$, and $(S P F)_{t}$ and $(A P F)_{t}$ limit the temperature-solubility space (dotted area), where the phenomenon of the substance solubility growth occurs. 
Between the fields $(B S P F)_{c_{r}}$ and $(T S P F)_{c_{r}}$ there is an energetic band (the area dashed horizontally), which is the solubility inertia zone, or the lack of solubility activity. One may assume the proper solubility, referred to zero temperature, without any external stimulus, meaning no heat delivered. (An analogy to the proper rigidity of a material; the material does not deform at all at the beginning, apart from its loading by a mechanical external stimulus.)

The solubility curve, comprised between the points $0-1$, is the envelope of the rightangled triangles, moving in both directions; with the horizontal leg being invariable and equal to a constant temperature $T$, whereas the vertical leg is changing respectively, rising while moving the triangle in the temperature direction.

Now one may come to integrate the equation (5). By integrating the equation, one should mark the limits of integrals of the total differentials. That means

$$
\int_{c_{r}^{0}+\Delta c_{r}}^{c_{r}^{0}+2 \Delta c_{r}+\left(c_{r}^{1}-c_{r}^{0}\right)} d c_{r}=\frac{\partial c_{r}}{\partial t} \int_{\Delta t}^{\Delta t+T} d t
$$

and further

$$
\left(c_{r}^{1}-c_{r}^{0}\right)+\Delta c_{r}=\frac{d c_{r}}{d t} T
$$

or

$$
\frac{d c_{r}}{\left(c_{r}^{1}-c_{r}^{0}\right)+\Delta c_{r}}=\frac{1}{T} d t
$$

One may notice, the partial derivative has been substituted by the quotient of the total differentials. It could be done that way because the total differentials have been clearly determined by introducing the limits of the integrals. result

Furthermore, by integrating both sides of the equation (8), one obtains the following

$$
\ln \left[\left(c_{r}^{1}-c_{r}^{0}\right)+\Delta c_{r}\right]=\frac{1}{T} t+C^{*}
$$

that is

$$
\left(c_{r}^{1}-c_{r}^{0}\right)+\Delta c_{r}=e^{\frac{t}{T}+C^{*}}=e^{C^{*}} \cdot e^{\frac{t}{T}}=C e^{\frac{t}{T}}
$$

After taking into account that for $t=0$, the magnitude $\Delta c_{r}=0$, one obtains

$$
C=c_{r}^{1}-c_{r}^{0}
$$

and after substituting (11) to (10), and then after regarding that $\Delta c_{r}=c_{r}-c_{r}^{0}$ 


$$
c_{r}=c_{r}^{0}+\left(c_{r}^{1}-c_{r}^{0}\right) \cdot\left(e^{\frac{t}{T}}-1\right)
$$

After substituting $c_{r}=c_{r}^{1}$ to the equation (12) one may determine the second coordinate of the final point of the curve, i.e. of the point „1". That coordinate is then expressed by the following dependence:

$$
t_{1}=T \ln 2
$$

The equation (12) is that model, or the function approximation, of which the parameters will be determined on the basis of experimental material.

Naturally, the tempo/rate, intensity, rate of changes of that solubility coefficient, should be also characterized. That intensity, denoted by a symbol $k$, is the first derivative (the derivative of the first order) of the solubility coefficient against temperature. Thus

$$
k=\frac{d c_{r}}{d t}=\frac{c_{r}^{1}-c_{r}^{0}}{T} e^{\frac{t}{T}}=k_{0} e^{\frac{t}{T}}
$$

For $t=0$ the intensity $k=k_{0}$, and for $t=t_{1}=T \ln 2$ that intensity $k=k_{1}=2 k_{0}$. Such a dependence has been illustrated in Fig. 4.

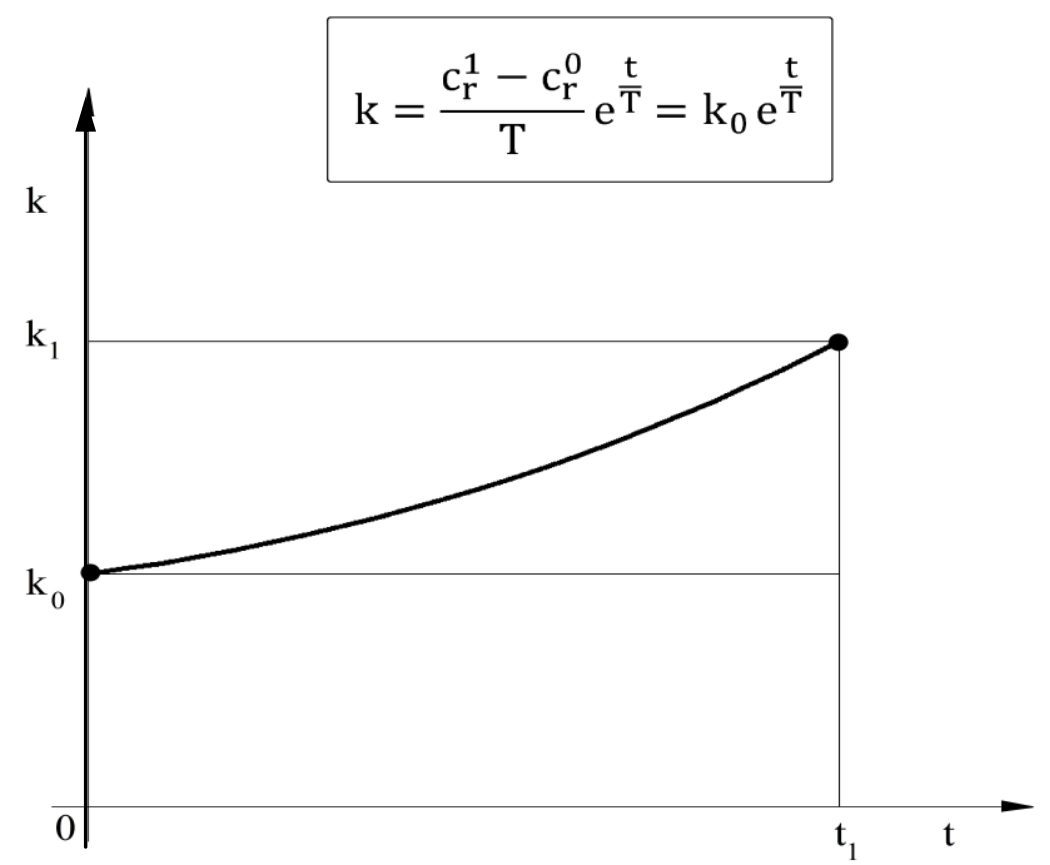

Fig. 4. Indicatrisse of dependence of the increment/growth intensity of the substance solubility coefficient on temperature of the aqueous solution 


\section{ADVANTAGE OF THE PRESENTED THEORY: AN EXAMPLE}

The presented theory has been used for adequate description of an exemplary chemical characteristics. This characteristics is the dependence of the solubility coefficient of a determined substance on the solution temperature; with the substance being the silver nitrate $\mathrm{AgNO}_{3}$, and water $\mathrm{H}_{2} \mathrm{O}$ as the solution. Table 1 presents the results: of temperature measurement and determination of the relating solubility coefficient of this nitrate in the environment of aqueous solution. Those experimental points form one of the three curves of solubility, as presented above in Fig. 1.

Table 1. Results of temperature measure and determination the corresponding solubility coefficient of silver nitride $\mathrm{AgNO}_{3}$ in the aqueous environment

\begin{tabular}{|c|c|c|c|c|c|c|c|c|c|c|}
\hline \multicolumn{10}{|c|}{ Temperature, ${ }^{\circ} \mathbf{C}$} \\
\hline 0 & 10 & 20 & 30 & 40 & 50 & 60 & 70 & 80 & 90 & 100 \\
\hline 1.22 & 1.70 & 2.22 & 3.00 & 3.76 & 4.55 & 5.25 & --- & 6.69 & --- & 9.52 \\
\hline
\end{tabular}

It is worth turning attention onto differentiation between these two metrology notions: measurement, and determination. The „measurement" does not require explanations as it is quite obvious. The „determination" needs a relevant development of the contents. That general notion, covers both the measurement, and calculations. Thus the temperature $t$ was measured, whereas the coefficient of solubility, just determined. That physical magnitude was determined because first the mass $M_{S}$ of the dissolved substance, used to saturate $M_{W}$ of water is measured in a determined temperature, which also undergoes a measurement. Afterwards, according to the essence of determination, the solubility coefficient of this substance is calculated. It has been closer explained by the amplification (development) of the formula (1) on the substance solubility coefficient, so

$$
c_{r}=\frac{m_{s}}{100 g H_{2} O}=\frac{M_{s}}{M_{w}}
$$

That terminology quest, on the background of many other problems of this type, has been explained in literature [18]. Some links of the developed terminology chain are analysed also in the works [19-21].

Taking advantage of the presented herewith the theory, first of all the values of coordinates $t_{i}^{*}$ should be determined; these coordinates determine the position of the straight/line, tangent to this searched analytic course of the solubility coefficient. These coefficients result from the formula (13), then

$$
t_{i}^{*}=\frac{t_{i}}{\ln 2}
$$

The results of calculations of these coordinates (Table 2) indicate, that they are bigger as to the values than the experimental coordinates. 
Table 2. Comparison of the magnitudes needed to calculate the coefficient values of linear regression

\begin{tabular}{|c|c|c|c|c|}
\hline$i$ & $C_{r}^{i}$ & $t_{i}^{*}$ & $\left(t_{i}^{*}\right)^{2}$ & $t_{i}^{*} \cdot \mathcal{C}_{r}{ }^{*}$ \\
\hline 1 & 1.22 & 0 & 0 & 0 \\
\hline 2 & 1.70 & 14.43 & 208.22 & 24.53 \\
\hline 3 & 2.22 & 28.86 & 832.90 & 64.07 \\
\hline 4 & 3.00 & 43.29 & 1874.02 & 129.87 \\
\hline 5 & 3.76 & 57.72 & 3331.60 & 217.03 \\
\hline 6 & 4.55 & 72.15 & 5205.62 & 328.28 \\
\hline 7 & 5.25 & 86.58 & 7496.10 & 454.55 \\
\hline 8 & 6.69 & 115.44 & 13326.39 & 772.29 \\
\hline 9 & 9.52 & 144.30 & 20832.40 & 1373.74 \\
\hline$\Sigma$ & 37.91 & 562.77 & 53107.34 & 3364.36 \\
\hline
\end{tabular}

The values of coordinates $t_{i}^{*}$ should be worked out statistically, by approximation them in accordance to the following relationship:

$$
c_{r}=c_{r}^{0}+k_{0} t_{i}^{*}
$$

For a generally recorded linear dependence of this type

$$
y=a+b x
$$

the coefficients $a$ and $b$ are determined according to the following formulae:

$$
\begin{array}{r}
b=\frac{n \sum_{i=1}^{n} x_{i} y_{i}-\sum_{i=1}^{n} x_{i} \sum_{i=1}^{n} y_{i}}{n \sum_{i=1}^{n}\left(x_{i}\right)^{2}-\left(\sum_{i=1}^{n} x_{i}\right)^{2}} \\
a=\frac{1}{n}\left(\sum_{i=1}^{n} y_{i}-b \sum_{i=1}^{n} x_{i}\right)
\end{array}
$$


which come from the use of the rule of the least sum of deviation squares of the experimental values from the theoretical ones, resulting from the position of the linear regression function. That rule has been described in detail in the references, for instance [22-25].

For the introduced denotations of the independent and dependent variables, i.e. $x_{i}=t_{i}^{*}$ and $y_{i}=c_{r}^{i}$, the formulae on the magnitudes $k_{0}$ and $c_{r}^{0}$ possess/take the following configurations:

$$
\begin{gathered}
k_{0}=\frac{n \sum_{i=1}^{n} t_{i}^{*} \cdot c_{r}^{i}-\sum_{i=1}^{n} t_{i}^{*} \sum_{i=1}^{n} c_{r}^{i}}{n \sum_{i=1}^{n}\left(t_{i}^{*}\right)^{2}-\left(\sum_{i=1}^{n} t_{i}^{*}\right)^{2}} \\
c_{r}^{0}=\frac{1}{n}\left(\sum_{i=1}^{n} c_{r}^{i}-k_{0} \sum_{i=1}^{n} t_{i}^{*}\right)
\end{gathered}
$$

In Table 2, the comparison of all magnitudes derived to calculate the values of the linear regression coefficients has been presented, concerning: initial coefficient of solubility $c_{r}^{0}$ and the initial intensity of the growth of the solubility coefficient, i.e. $k_{0}$. Therefore

$$
\begin{gathered}
k_{0}=\frac{9 \cdot 3364.36-562.77 \cdot 37.91}{9 \cdot 53107.34-(562.77)^{2}}=0.055 \frac{1}{{ }^{o} C} \\
c_{r}^{0}=\frac{1}{9}(37.91-0.055 \cdot 562.77)=0.77
\end{gathered}
$$

Thus

$$
c_{r}=0.77+0.055 t_{i}^{*}
$$

The temperature constant $T$, resulting from the formula (13), takes the form

$$
T=\frac{t_{1}}{\ln 2}
$$

but now it may be determined from the formula

$$
k_{0}=\frac{c_{r}^{1}-c_{r}^{0}}{T}
$$

meaning that

$$
T=k_{0}\left(c_{r}^{1}-c_{r}^{0}\right)
$$

By substituting the values of particular magnitudes 


$$
\begin{gathered}
\left(k_{0}=0.055 \frac{1}{{ }^{o} C} ; c_{r}^{1}=9.52 ; c_{r}^{0}=0.77\right), \text { to the formula (28), one obtains } \\
T=0.055(9.52-0.77)=159{ }^{\circ} \mathrm{C}
\end{gathered}
$$

Thus, according to the formula (13)

$$
t_{1}=159 \ln 2=110^{\circ} \mathrm{C}
$$

Now the final quantitative form of the dependence $c_{r}=f(\mathrm{t})$ for the phenomenon of solubility of silver nitrate in water may be obtained; it is obtained through the introducing of the following values of the constants: $c_{r}^{0}=0.77 ; c_{r}^{1}=9.52 ; T=159^{\circ} \mathrm{C}$, to the formula (12). Therefore

$$
c_{r}=0.77+(9.52-0.77)\left(e^{\frac{t}{159}}-1\right)=0.77+8.75\left(e^{\frac{t}{159}}-1\right)
$$

The graphic illustration of the former dependence (Fig. 5) finally allows to note the main advantage, resulting from the adequate description of the phenomenon of the chemical substance solubility. The advantage comes from the description represented by the reason model class, having also a physical sense. One may notice, that all elements of the presented description are the physical magnitudes; it concerns both the variables (dependent and independent) and constants.

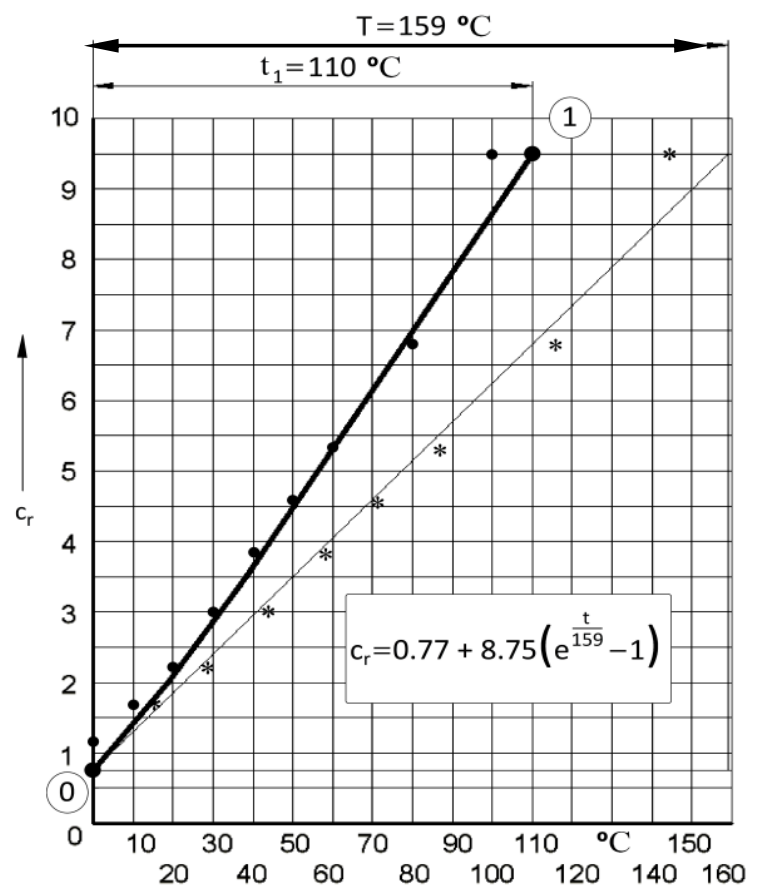

$\mathrm{t}$

Fig. 5. Dependence of solubility coefficient of silver nitride $\mathrm{AgNO}_{3}$ on the aqueous solution solubility 
The intensity of changes of the solubility coefficient, referred to the relationship (31), has the following form:

$$
k=\frac{d c_{r}}{d t}=\frac{8.75}{159} e^{\frac{t}{159}}=0.055 e^{\frac{t}{159}}
$$

so that for $t=0$ the intensity $k=k_{0}=0.055 \frac{1}{{ }^{o} C}$, and for $t=t_{1}=T \ln 2=159 \ln 2$ that intensity $k=k_{1}=2 k_{0}=0.11 \frac{1}{{ }^{o} \mathrm{C}}$. That relationship has been also illustrated graphically in Fig. 6 .

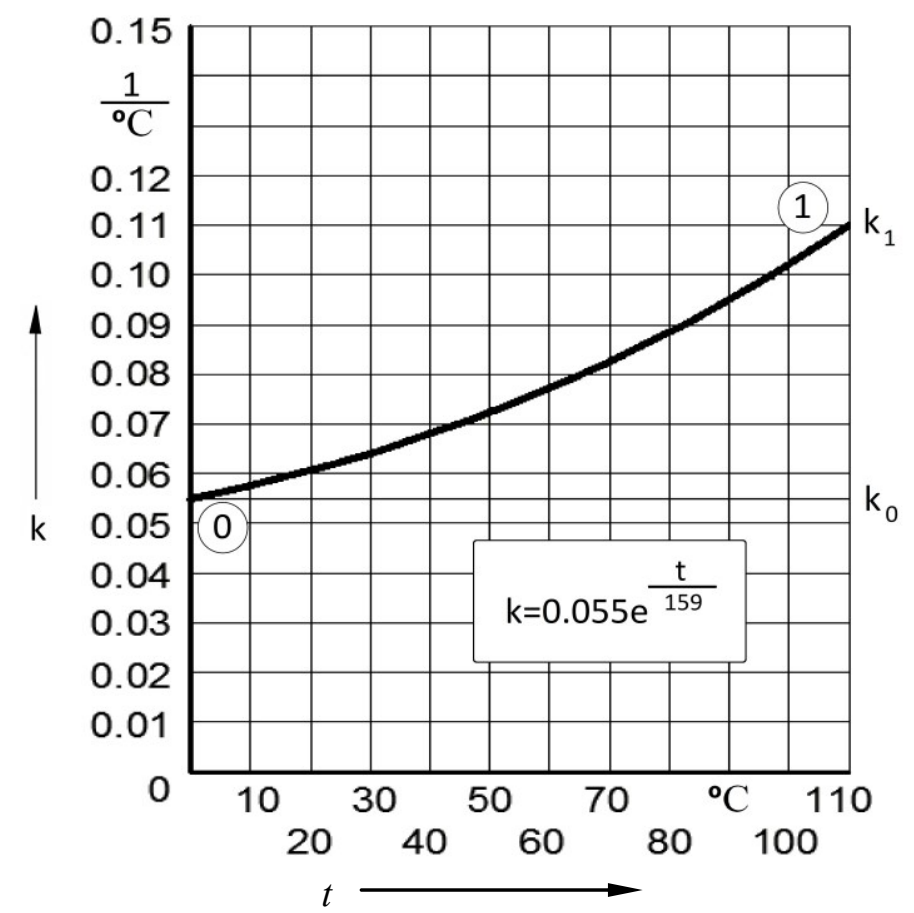

Fig. 6. Dependences of intensity of the solubility coefficient variability of silver nitride $\mathrm{AgNO}_{3}$ on temperature of aqueous solution

\section{CONCLUSION}

In the conclusion it is worth stressing the essence of the presented manner of description of the phenomenon of the chemical substance solubility in aqueous environment. This description is adequate in character, possessing the nature of reason models, i.e. having a physical sense. That model is in a contradiction to the description models, commonly used in the statistical elaboration of experimental data.

The significance is getting on the cognitive way from the source, being the source differential equation. That made it possible to derive a true final form of the dependence of the solubility coefficient of the studied chemical substance on temperature of aqueous solution.

It is worth noting an enormous application of the source differential equation. In the work [2], it was used to the description of elastic grinding wheel characteristics. The work [26] presents its use in reference to non-continuous, very complex dependence of the tool life 
under cut on the main velocity of one of the elements of the machining system. In another authors' work [27], a new approach to the description of the tool edge behaviour fixed flexibly has been presented.

That is not the end of usage/application of the source differential equation. The exemplary phenomena, with the description having their beginning in the structure of the source differential equation (Fig. 7), show the really big significance on the cognitive ground.

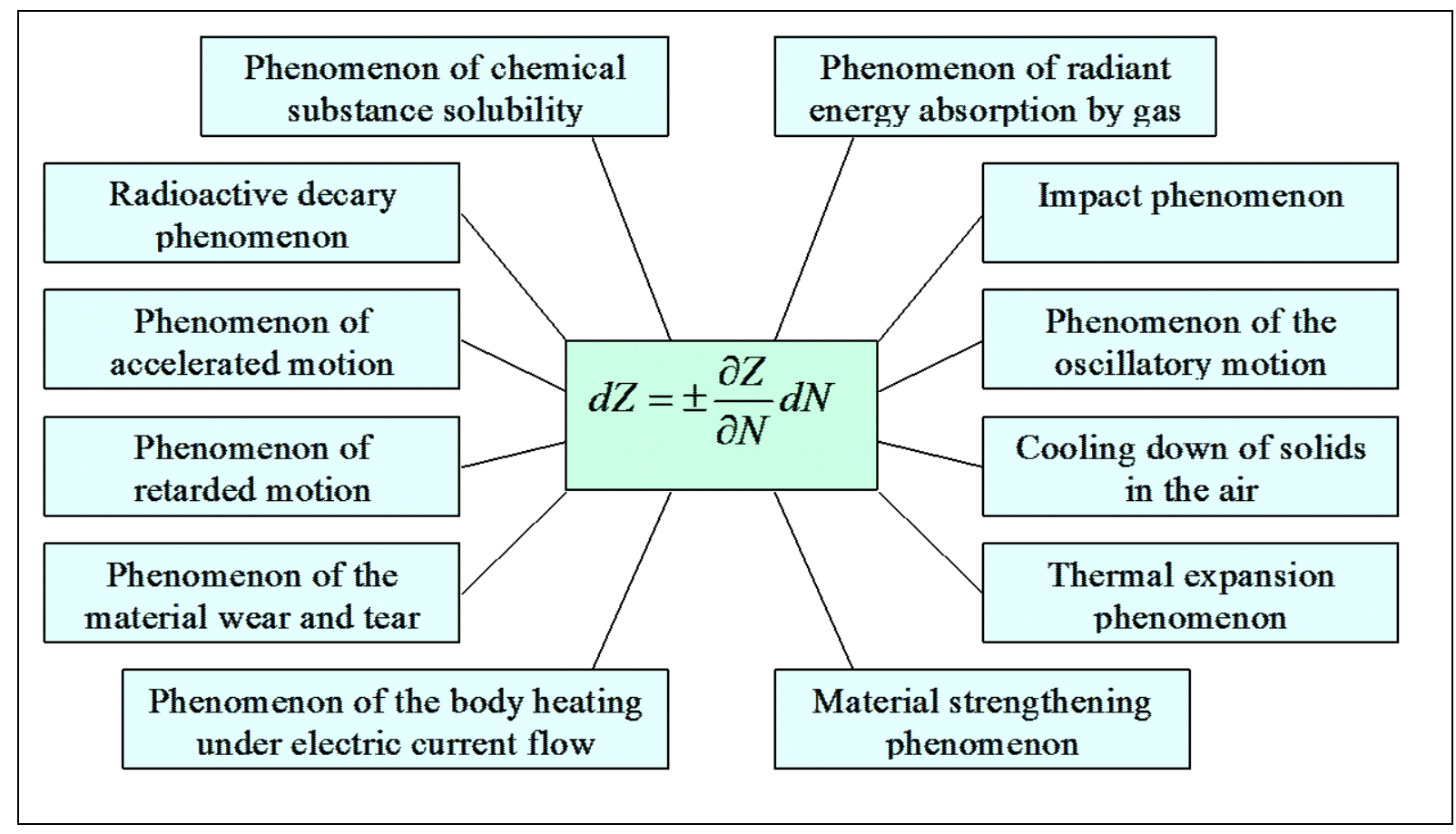

Fig. 7. Some exemplary phenomena with the beginning in the structure of source differential equation

\section{REFERENCES}

[1] Robert Hooke, Douglas Shaffer, Mathematical models and reality (Modele matematyczne a rzeczywistość). PWN, Warszawa 1969 (transl. from English).

[2] Zdzisław Pluta, Fundamentals of surface smoothing by elastic abrasive wheels (in Polish). Wydawnictwo Politechniki Koszalińskiej, Koszalin 2007.

[3] Zdzisław Pluta, $L A B$ 10(5) (2005) 40-43.

[4] J. Balejko, $L A B$ 9(2) (2004) 15-17.

[5] F. Shahidi, J. Synowiecki, J. Balejko, Utilization of seal meat byproducts.

Proc. of the 38th International Congress of Meat Science and Technology. August 23-28, 1992, Clermont-Ferrand, France, 5919-5920.

[6] F. Shahidi, X.Q. Han, J. Synowiecki, J. Balejko, Enzymatic modification of Marine proteins: 1. Male and spent capelin. Proc. of the 37th Atlantic Fisheries Technological Conference. August 23-26, 1992, Perce, Quebec, Canada.

[7] F. Shahidi, J. Synowiecki, J. Balejko, Journal of Agricultural and Food Chemistry, 42(11) (1994) 2634-2638.

[8] W. Trzebiatowski, Non-organic chemistry (Chemia nieorganiczna). PWN, Warszawa 1966, 4th edition. 
[9] A. Kozakiewicz, Chemistry (Chemia). PWRiL, Warszawa 1978, 1st edition.

[10] P.P. Durrant, B. Durrant, Contemporary non-organic chemistry (Zarys współczesnej chemii nieorganicznej). PWN, Warszawa 1965 (transl. from English).

[11] R. B. Heslop, P. L. Robinson, Non-organic chemistry (Chemia nieorganiczna). PWT, Warszawa 1954 (transl. from English).

[12] H. Remy, Lehrbuch der anorganischen Chemic, 10th ed., Leipzig, 1960.

[13] M. Koszmider, Chemistry exercises for high school (Chemia dla szkół średnich w zadaniach). WSiP, Warszawa 1997, 2nd ed.

[14] S. Karbownicki, M. Kozikowski, General chemistry (Chemia ogólna). Wydawnictwo Politechniki Częstochowskiej, Częstochowa 1967.

[15] Zdzisław Pluta, Forum Akademickie 6(3) (1999) 58-60.

[16] Tadeusz Hryniewicz, Zdzisław Pluta, Understanding the Teaching Process or the Lost Essence of Energy, Proc. of the $8^{\text {th }}$ World Conference on Continuing Engineering Education, Therne A.: Knowledge, Skills and Competency, May 12-16, 2001, Toronto, Ontario, Canada, pp. 25-31.

[17] Zdzisław Pluta, Energetyka 613(7) (2005) 496-501.

[18] M. Mazur, Technical terminology (Terminologia techniczna). WNT, Warszawa 1961.

[19] Zdzisław Pluta, Normalizacja 62(7) (1994) 17-18.

[20] Zdzisław Pluta, Normalizacja 62(8) (1994) 16-17.

[21] Zdzisław Pluta, Normalizacja 62(9) (1994) 10-11.

[22] K. Mańczak, Technics of experiment planning (Technika planowania eksperymentu). WNT, Warszawa 1976.

[23] H. Szydłowski (ed.), Measurement theory (Teoria pomiarów). PWN, Warszawa 1978.

[24] E. Bright Wilson, Jr., Introduction to scientific studies (Wstęp do badań naukowych). PWN, Warszawa 1968 (transl. from English), 2nd edition.

[25] W. E. Deming, Statistical Adjustment of Data, New York 1938, Wiley.

[26] Zdzisław Pluta, Tadeusz Hryniewicz, Int. J. Adv. Manuf. Technol. 51 (2010) 35-43, DOI:10. 1007/s 00170-010-2595-5.

[27] Zdzisław Pluta, Tadeusz Hryniewicz, Int. J. Adv. Manuf. Technol. 62(5) (2012) 529-542, DOI:10. 1007/s 00170-011-3813-5 